ВІСНИК

ОДЕСЬКОГО НАЦІОНАЛЬНОГО

МОРСЬКОГО УНІВЕРСИТЕТУ
HERALD

OF THE ODESSA NATIONAL

MARITIME UNIVERSITY № 2 (65), 2021

УДК 621.824

DOI 10.47049/2226-1893-2021-2-138-151

\title{
ИССЛЕДОВАНИЕ ФРЕТТИНГ-ПРОЦЕССОВ ПРИ ЦИКЛИЧЕСКОМ ИЗМЕНЕНИИ НАПРЯЖЕННОГО СОСТОЯНИЯ В ПЯТНЕ КОНТАКТА
}

\author{
А.В. Кобзарук \\ к.т.н., доцент кафедры «Технология материалов» \\ Одесский наџиональный морской университет, Одесса, Украина \\ В.И. Бабинец \\ супервайзер Ильичевского судоремонтного производства
}

Аннотация. На основе литературного обзора экспериментальных данных разработана методика исследования прочессов, происходящих в пятне контакта при фреттинге на воздухе и в морской воде. Экспериментальные исследования фреттинг-процессов на специально изготовленной испьтательной машине дали возможность изучить все этапь фреттинг-разрушения, начиная с приработки контактируюших пар материалов вплоть до образования фреттинг-усталостных трещин.

Ключевые слова: фреттинг-прочесс, пятно контакта, фреттинг-усталость.

\section{УДК 621.824}

DOI 10.47049/2226-1893-2021-2-138-151

\section{ДОСЛІДЖЕННЯ ФРЕТТИНГ-ПРОЦЕСІВ ПРИ ЦИКЛІЧНІЙ ЗМІНІ НАПРУЖЕНОГО СТАНУ У ПЛЯМІ КОНТАКТУ}

\author{
О.В. Кобзарук \\ к.т.н., доцент кафедри «Технологія матеріалів» \\ Одеський національний морський університет, Одеса, Україна
}

\section{B.I. Бабінець}

супервайзер Іллічівського судноремонтного виробництва

Анотація. На основі літературного огляду експериментальних даних розроблена методика дослідження процесів, щуо відбуваються в зоні контакту при фреттинзі на повітрі та в морській воді. Експериментальні дослідження фреттинг-процесів на спеціально виготовленій випробувальній машині дали змогу вивчити всі етапи фреттинг-руйнування, починаючи з підробітки контактуючих пар аж до утворення фреттинг-втомних трещзін.

Ключові слова: фреттинг-прочес, пляма контакту, фреттингвтома.

(C) Кобзарук А.В., Бабинец В.И, 2021 
UDC 621.824

DOI 10.47049/2226-1893-2021-2-138-151

\title{
RESEARCH OF FRETTING PROCESSES IN CYCLIC CHANGES IN THE VOLTAGE STATE AT THE CONTACT SPOT
}

\author{
Kobzaruk Olexander \\ Candidate of Technical Sciences, \\ Associate Professor of the Department of «Materials Technology» \\ Odessa National Maritime University, Odessa, Ukraine
}

Babinets Valery

supervisor of the Illichivsk ship repair production

\begin{abstract}
On the basis of a literature review of experimental data, a technique has been developed for studying the processes occurring in the contact patch during fretting in air and in seawater. Experimental studies of fretting processes on a specially made testing machine made it possible to study all stages of fretting fracture, from the running-in of contacting pairs up to the formation of fretting fatigue cracks.
\end{abstract}

Keywords: fretting process, contact patch, fretting fatigue.

Введение. Фреттинг-разрушение (фреттинг-коррозия, фреттингусталость, фреттинг-износ) является весьма распространенным видом повреждения деталей машин в соединениях. Примерами таких соединений могут служить замковые соединения лопаток в диске турбины, фланцевые соединения, оси и валы под напрессованными подшипниками, валы в узлах прессовых соединений и другие детали общего и судового машиностроения. К наиболее ответственным узлам соединения деталей, подверженных фреттингу, относится судовой гребной вал (рис.1).

От его безотказной работы зависит не только эксплуатационная надежность судна, но и уменьшение валютных затрат в связи с возможной заменой вала или его ремонтом, не говоря о тяжелых последствиях в случае поломки вала в открытом море.

Несмотря на то, что фреттинг-повреждения давно известны и достаточно широко исследованы как отечественными [1-5], так и зарубежными [6 и др.] учеными, процессы фреттинга изучены недостаточно, в том числе и в практике эксплуатации судовых технических средств. Явления, происходящие в подступичной части прессового соединения при условии раздельного и суммарного воздействия силовых факторов и коррозионной среды, имеющие место в эксплуатационной практике, не нашли широкого отражения в литературе. 


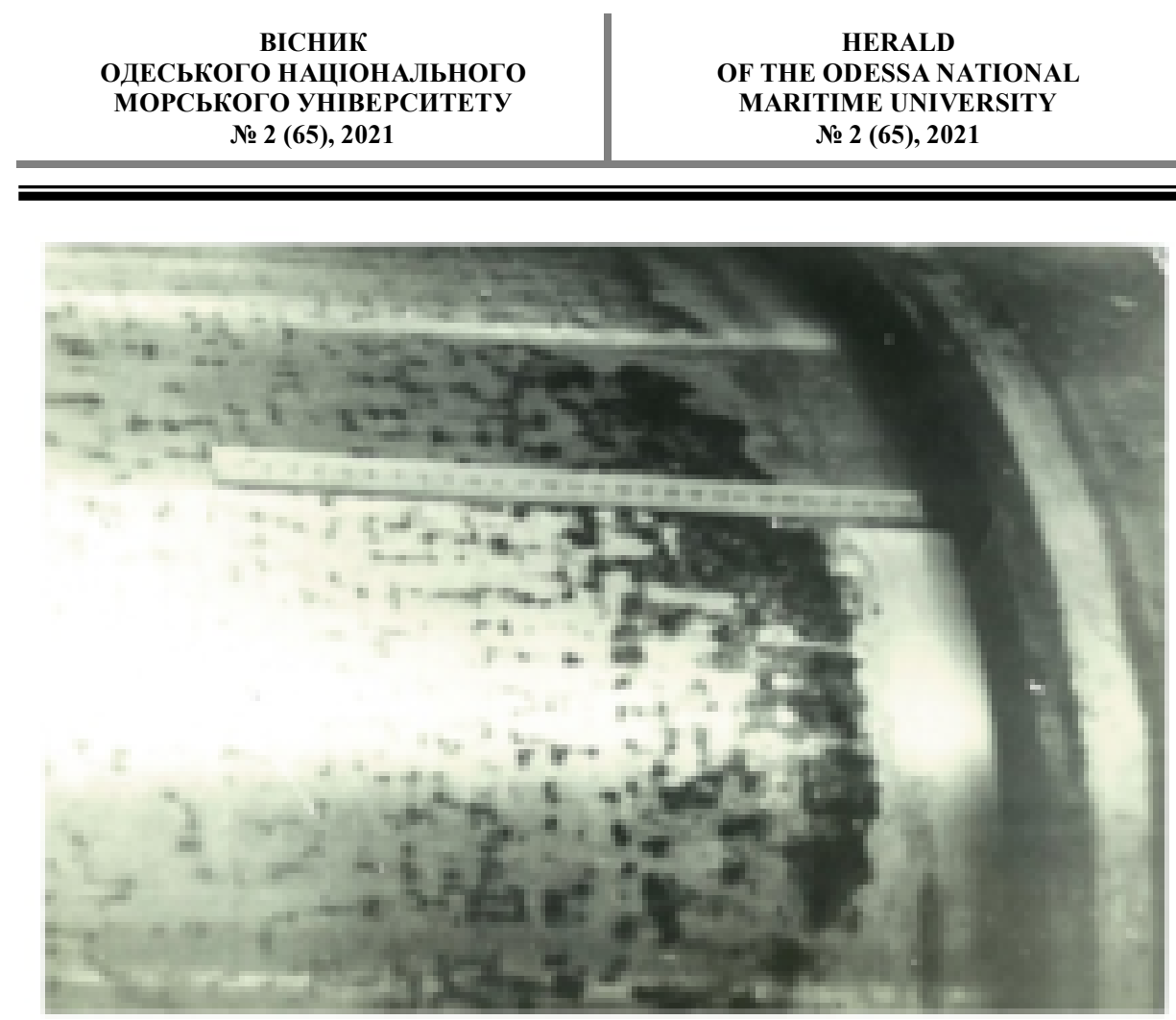

Рис.1. Фреттинг-коррозия на конусе гребного вала Ø 860 мм под латунной ступищей винта

Многочисленные фреттинг-повреждения судовых гребных валов в подступичной части классифицируются [1] следующим образом: 1) легкое повреждение от фреттинг-коррозии; 2) налипание метелла ступицы на вал и вырывы; 3) возникновение зародышевых усталостных трещин; 4) развитие трещин; 5) усталостный излом.

Эксплуатационные повреждения деталей общего и судового машиностроения свидетельствуют о том, что фреттинг-процессы оказывают большое влияние на сопротивление усталости деталей в сопряжениях. На большинстве обследованных объектов обнаруживаются усталостные трещины, берущие свое начало в зоне, пораженной фреттингом (рис. 2).

Было установлено, что выносливость вала с насаженной ступицей, под которой развиваются фреттинг-процессы, на 40-60 \% ниже выносливости гладкого вала. А по данным некоторых отечественных и зарубежных авторов сопротивление усталости вследствии фреттинга может достигать $85 \%$. Степень влияния поверхностных поражений, развивающихся при фреттинге, определяли, нанося фреттинг-повреждения на поверхность вала различной величины. На (рис. 3) представлены основные схемы фреттинг-усталостных испытаний, которые соответствуют реальным условиям работы ряда узлов механизмов и машин. 
ВІСНИК

ОДЕСЬКОГО НАЦІОНАЛЬНОГО

МОРСЬКОГО УНІВЕРСИТЕТУ

№ 2 (65), 2021
HERALD

OF THE ODESSA NATIONAL

MARITIME UNIVERSITY № 2 (65), 2021

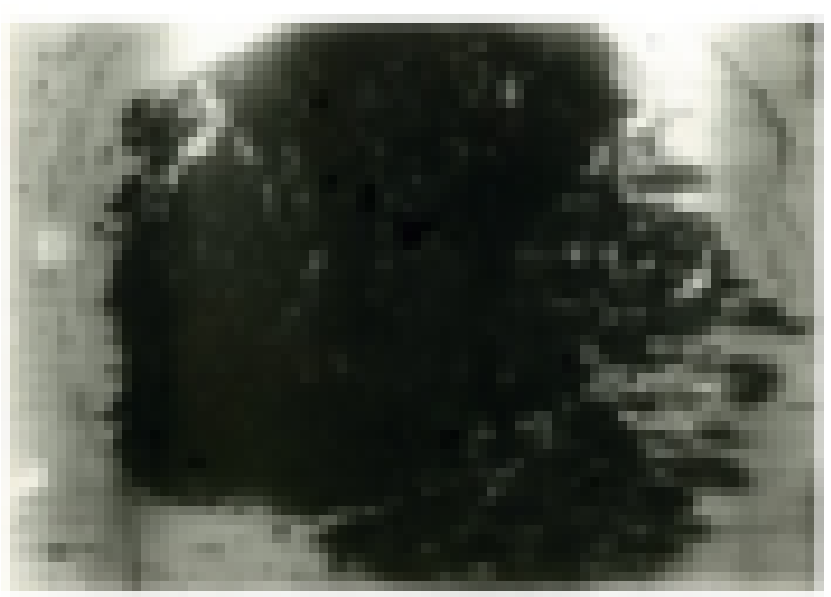

Рис. 2. Фреттинг-усталостные трещины в кольцевой зоне поражения фреттингом

Причем, чаще поврежденные участки оказываются более опасными, нежели места деталей с концентрацией напряжений от перемены сечения, наличия шпоночных канавок либо отверстий. Наибольшее влияние фреттинга проявляется при незначительных циклических напряжениях.

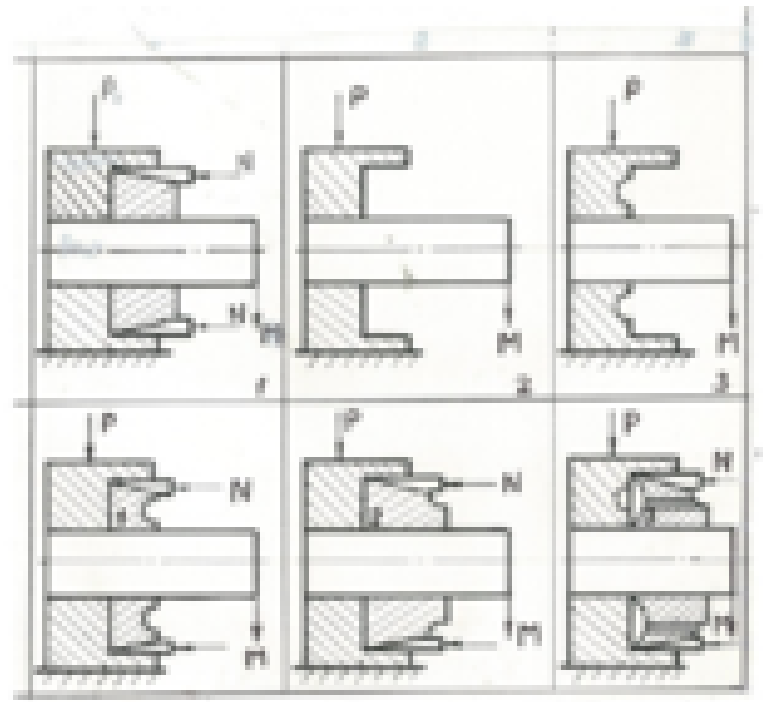

Рис. 3. Схемы нагружения моделей прессовых соединений при испытании на усталость 
Было установлено, что выносливость вала с насаженной ступицей, под которой развиваются фреттинг-процессы, на 40-60 \% ниже выносливости гладкого вала. А по данным некоторых отечественных и зарубежных авторов сопротивление усталости вследствии фреттинга может достигать $85 \%$. Степень влияния поверхностных поражений, развивающихся при фреттинге, определяли нанося фреттинг-повреждения на поверхность вала различной величины. На (рис. 3) представлены основные схемы фреттинг-усталостных испытаний, которые соответствуют реальным условиям работы ряда узлов механизмов и машин.

Большинство авторов едины во мнении, что основная опасность снижения сопротивления усталости детали в сопряжении заключается в действии контактного давления (например, между ступицей и валом) и возникновении на поверхности нормальных, касательных и изгибных напряжений. При передаче нагрузки на поверхности контакта сопряженных деталей могут появиться дополнительные касательные напряжения, которые увеличивают опасность разрушения сопряженных деталей в местах повышенных удельных давлений, где под влиянием периодических рабочих нагрузок возникают относительные смещения контактных поверхностей. Наличие контактного давления между сопрягаемыми поверхностями и амплитуды их относительного смещения обуславливают появление повреждений от фреттинга.

Цель работы. С целью исследования фреттинг-процессов, влияния статического и циклического напряженного состояния сжатия или растяжения в пятне контакта при одновременном действии нормальных и касательных усилий, а также независимого контролируемого перемещения контртела в контакте с образцом, деформируемым изгибом на процесс развития усталости в зоне локального контакта изготовлено специальное устройство [7]. Схема устройства представлена на рис. 4. Общий вид машины для испытаний - на рис. 5.

Образец для испытаний выполнен в виде пластины из стали 45 с переменной шириной, обеспечивающей постоянство напряжений изгиба от сечения к сечению, т.е. является балкой равного сопротивления изгибу (рис. 6). Контробразцы двух радиусов кривизны, изготавливались из разных материалов: стали, меди и капролона.

Отличительной особенностью данной методики исследования фреттинг-процессов, по сравнению с существующими, является возможность создания в пятне контакта независимого напряженного состояния от нормального Рн и касательного Рк усилий в одном случае и изгиба (в том числе циклического) в другом.

Плавная регулировка частотных характеристик приводных устройств нагружения позволяла управлять резонансными явлениями от действия меняющихся полей напряжений и деформаций. Эти исследования проводились при периодическом измерении параметров, характеризующих усталостные процессы. 
Методика. При исследовании поверхности, подвергнутой фреттинг-процессам, в пятне контакта наблюдаются повреждения в виде локального «сваривания», питтингов, свободных продуктов износа и усталостных трещин (рис. 2). Полагают, что образование трещин связано с появлением больших растягивающих напряжений по контуру пятна контакта [8]. Значение этих напряжений существенно увеличивается под действием касательных усилий Рк на поверхности контакта. При этом касательные напряжения перераспределяются с концентрацией на поверхности пятна [9].

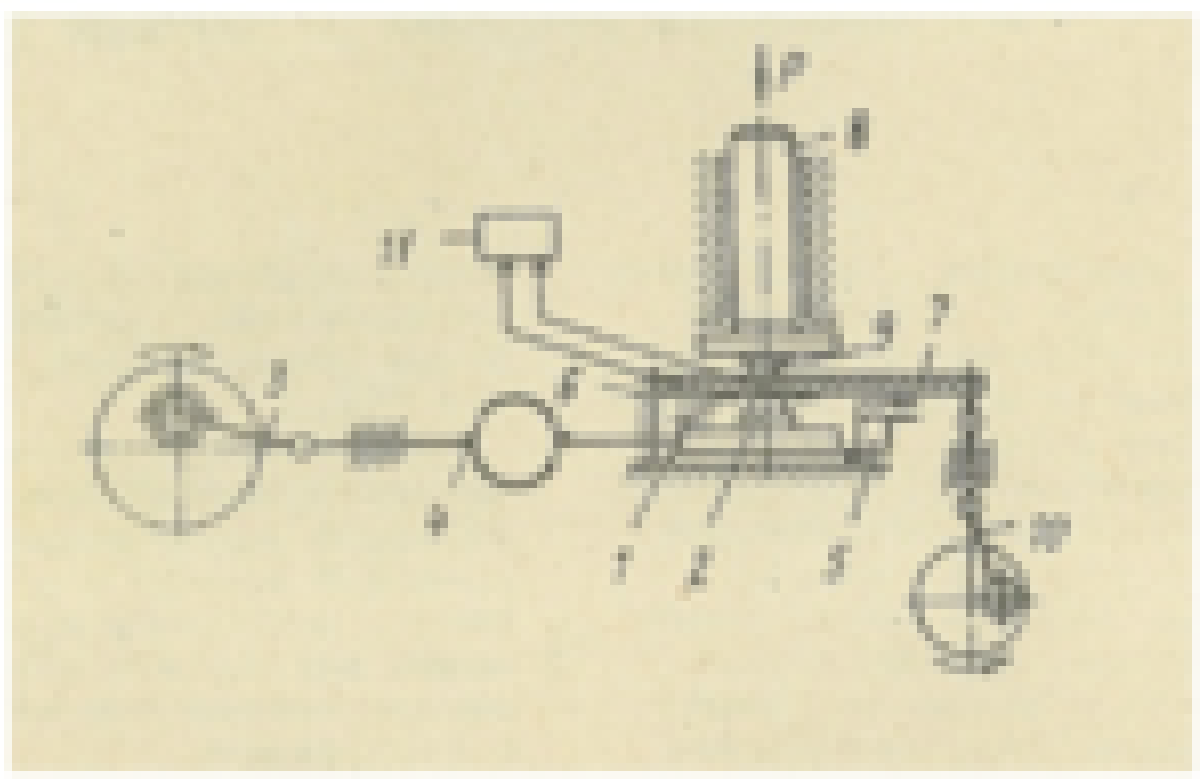

Рис. 4. Схема устройства для испытания материалов на износ при ииклическом изменении напряженного состояния:

\section{1-держатель контробразиа 2;}

3-привод возвратно-поступательного движения держателя;

4-динамометр; 5-детектор изменения амплитуды держателя 6 образиа; 7, 8-плунжер для нормального нагружения с наконечником;

9, 10-привод изгиба образиа, 11- измеритель деформаџии

При испытании на фреттингг-износ, фреттинг-коррозию, фреттинг-усталость повреждаемость оценивали измерением потери массы, измерением микротвердости, определением нормального сближения на контакте и глубины лунки фреттинга, топографированием поверхности, измерением электросопротивления на контакте, коэффициента трения контактирующих поверхностей, изменением площади фактического контакта. Проводились метеллографические исследования с фиксацией момента возникновения и развития микротрещин в очагах фреттинга. 

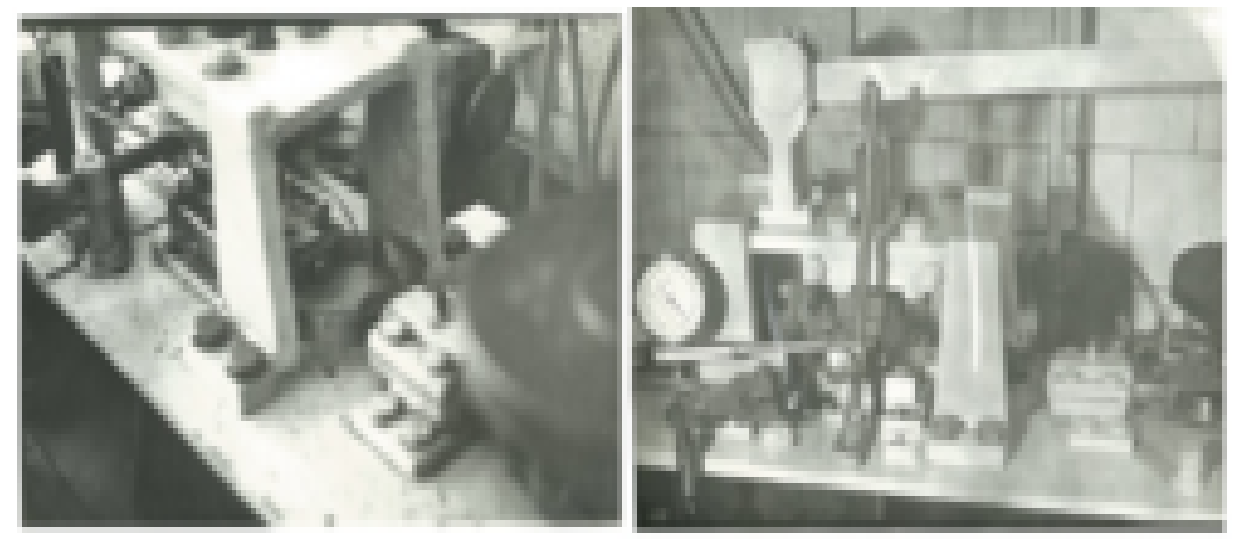

Рис. 5. Общий вид основных узлов испытательной машины

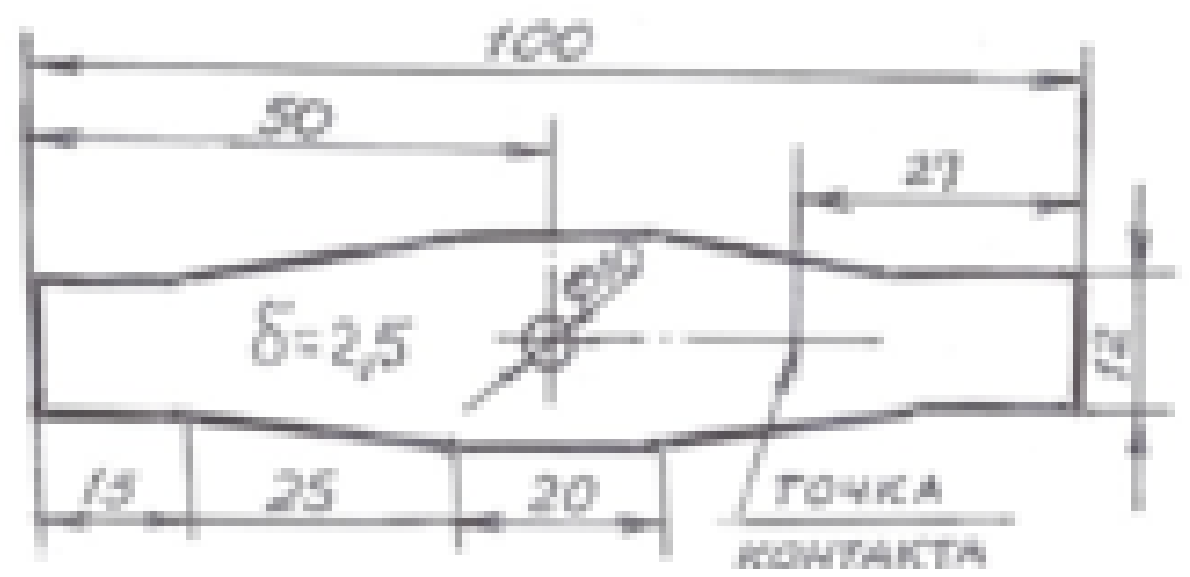

Рис. 6. Образеи для испытания материалов на износ при иииклческом изменении напряженного состояния

Из всех критериев трещинообразование наиболее точно характеризует опасное состояние нагруженной зоны контакта в соединении, вследствии которого могут быстро развиться усталостные трещины, способные привести к разрушению детали [10].

Одной из задач применения новой методики исследования являлось определение влияния изгибающих нагрузок на снижение сопротивления фреттинг-усталости широко применяемой в машиностроении стали 45 , а также установление закономерности ее повреждаемости при фреттинге в зависимости от природы некоторых конструкционных материа- 
лов. Решение поставленной задачи проводилось путем сравнительных испытаний по схеме контакта сферической поверхности контртела с плоским образцом. Такая схема позволила достаточно точно фиксировать количественные и качественные изменения параметров зоны фреттинга, топографировать зону повреждения и наблюдать за процессом разрушения.

Фреттинг-усталостные испытания проводились в три этапа. На первом этапе изучали влияние на повреждаемость в пятне контакта от действия только нормальной нагрузки, изменяющейся от 0 до 415,8 H с частотой 10 Гц. В процессе второго этапа к постоянно действующему нормальному усилию добавляли касательное усилие. На третьем этапе к совместному действию нормальной и касательной сил добавляли нагружение изгибом. Таким образом каждый этап исследования закономерностей разрушения отличался добавлением дополнительной нагрузки на контакте. На последнем этапе моделировались сложные условия нагружения. Исследовали и влияние различного сочетания действующих в пятне контакта сил на фреттинг- усталость. На всех этапах исследования испытания проводились при идентичных условиях нагружения нормальной силой, одном значении амплитуды относительного перемещения, одной частоты циклического изгиба и возвратно-поступательного движения контробразца.

Развитие фреттинг-разрушения в процессе сравнительных испытаний выбранных пар материалов при различных схемах нагружения оценивалось по изменению площади пятна контакта $\mathrm{S}$, взаимного сближения $\delta$ на контакте, глубины очага повреждения h испытуемого образца, величины коэффициента трения $\mu$. Проводили профилографирование лунки фреттинга и определяли долговечность до появления усталостных трещин у границ пятна контакта.

Испытания по выявлению влияния пульсирующей нормальной нагрузки на повреждаемость в пятне контакта, проводились в среде атмосферы на трех парах материалов: «сталь-сталь», «сталь-медь», «сталькапролон».

При испытании всех пар материалов на поверхности образцов в местах контакта с контртелом наблюдались пятна фреттинга округлой формы. Поверхностных кольцевых трещин при выбранной продолжительности испытаний $\left(30 \cdot 10^{3}\right.$ цикл), частоте и значении синусоидально изменяющейся нагрузки, обнаружено не было.

Наблюдаемые повреждения дают возможность оценить влияние пульсирующей нормальной силы на разрушение в зависимости от находящихся в контакте пар материалов (рис. 7). Измерение взаимного сближения на контакте через определенные промежутки времени показало наибольшие разрушения в начальный период испытаний. 


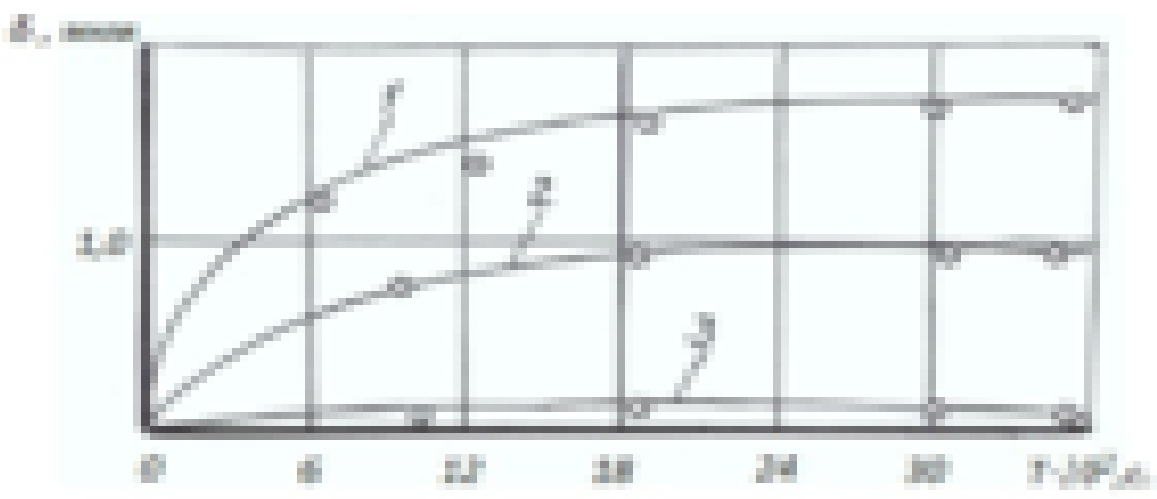

Рис. 7. Взаимное сближение на контакте при действии нормальной силь:

1-сталь-сталь; 2-сталь-медь; 3-сталь-капролон

Примерно через 36 тыс. циклов этот параметр для пары «стальсталь» стабилизировался, что свидетельствовало о начале «приработки» пары. Аналогичная картина наблюдалась и в других контактных парах и отличалась лишь глубиной разрушения. Появление касательного усилия на контакте, нагруженного постоянно действующей нормальной силой, ускорило накопление повреждений (рис. 8).

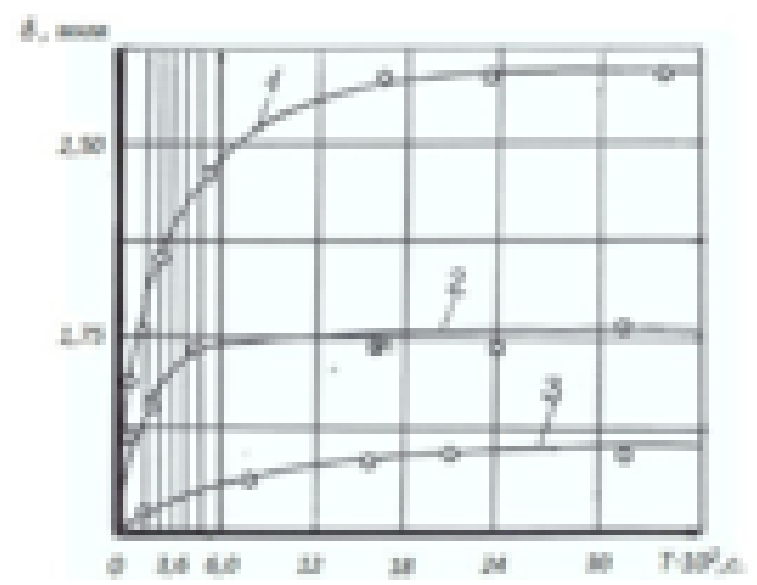

Рис. 8. Взаимное сближение на контакте при одновременном действии нормальных и касательных сил на воздухе:

1-сталь-сталь; 2-сталь-медь; 3-сталь-капролон 
ВІСНИК

ОДЕСЬКОГО НАЦІОНАЛЬНОГО МОРСЬКОГО УНІВЕРСИТЕТУ № 2 (65), 2021
HERALD

OF THE ODESSA NATIONAL

MARITIME UNIVERSITY № 2 (65), 2021

При контакте стали со сталью и стали с медью взаимодействие поверхностей стабилизировалось в 4 раза быстрее, т.е. во столько раз была выше скорость «приработки». Новые условия испытаний повлияли и на увеличение абсолютных значений $\delta$ на контакте (рис. 7 и 8)

Процесс приработки в пятне завершается в основном в начальный период испытаний, о чем свидетельствует изменение коэффициентов трения (рис. 9) и относительного сближения (рис. 7 и 8), происходящих, главным образом, в интервале 0-9000 циклов. Такие изменения на контакте были характерны для двух пар материалов: сталь-сталь и сталь-медь независимо от среды в зоне контакта.

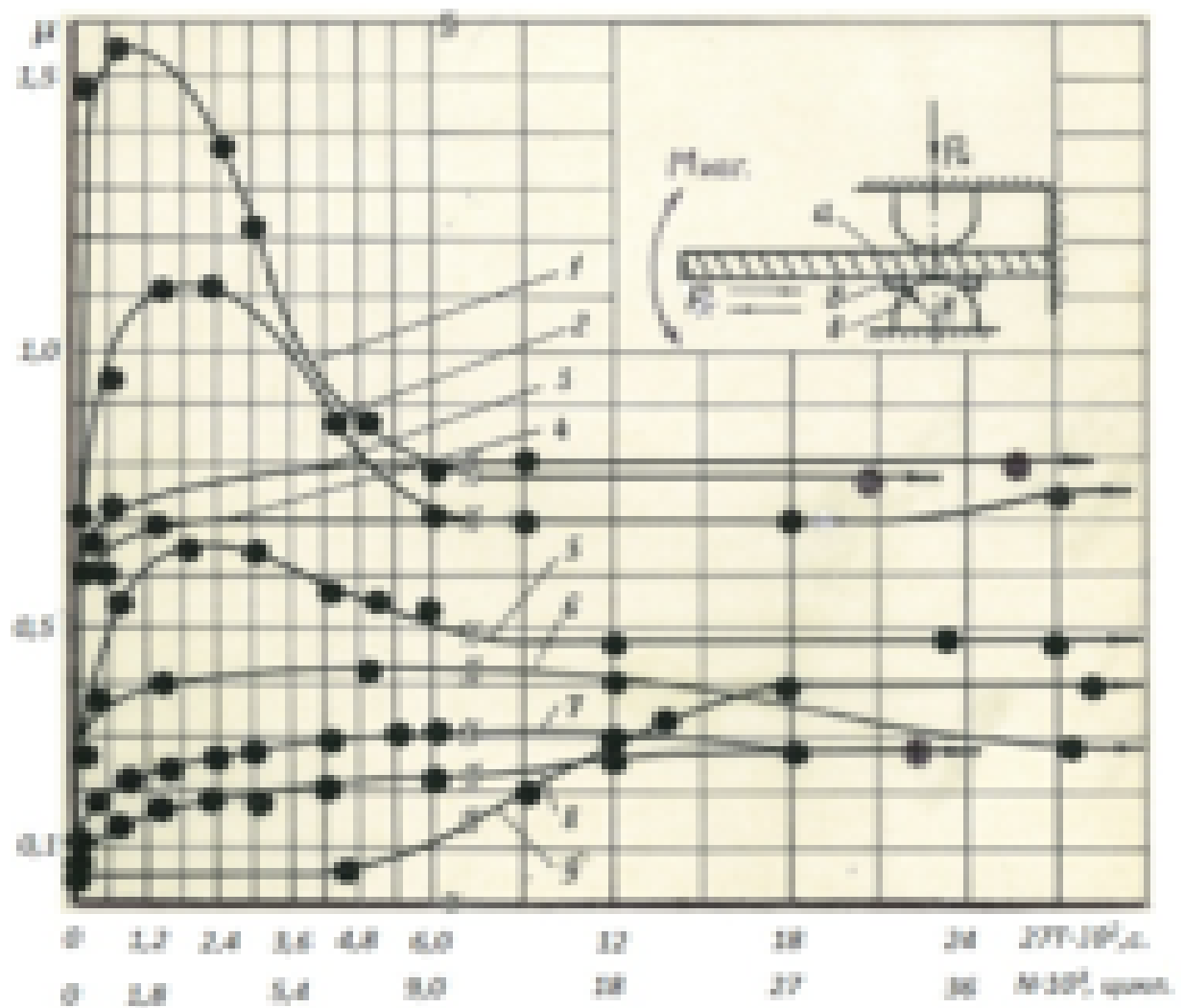

Pис. 9. Коэффициент трения н на контакте на воздухе:

1 -сталь-медь, $R=6$ мм; 2 - сталь-медь, $R=30 ; 3$-сталь-сталь, $R=6 м$; 4 - сталь-сталь, $R=30$ мм; 9 - сталь-капролон, $R 30$;

в морской воде: 5-cталь-медь, $R=30 м м$; 6 -сталь-сталь, $R=6 м$; 7 - сталь-капролон, $R=30$ мм; 8 -сталь-капролон + протектор, $R=30$

( $а$-стальной образец; б- протектор; в-контробразеи) 
Продолжительность стабилизации процессов разрушения на контакте стали с капролоном при испытании на воздухе отличалась от предыдущих пар. Отмечено, что после некоторой приработки (7 тыс. циклов) пары «сталь-капролон» повышается температура, что по всей вероятности, влияет на степень разрушения капролона в месте контакта. Процесс приработки наблюдался в промежутке от 7 до 27 тыс. циклов.

При испытании стали в контакте с медью коэффициент трения на воздухе в начальной стадии контактирования наибольший. Это согласуется с результатами, приведенными в работе [10]. Процессу приработки предшествует сваривание на контакте с последующим разрушением мостиков сварки и углублением лунки.

В морской воде контакт стали с медью обусловливает граничное разрушение стали по электромеханическому механизму. Сталь с более отрицательным электродным потенциалом, чем медь становится анодом и интенсивно окисляется. Разрушение поверхности происходило в приграничной зоне контакта. Эта зона находилась в напряженно-деформированном состоянии, которое меняло знак синхронно с частотой возвратнопоступательного движения контртела. Механическая активация металла в зоне контакта при испытании в коррозионной среде усиливала повреждаемость соприкасающихся поверхностей при фреттинге. Этим, оче-видно, можно объяснить сравнительно низкий предел выносливости валов прессовых соединений в морской воде с медной вставкой в торце ступицы [5].

Кроме характерных для той или иной пары процессов можно отметить общую для них закономерность. С увеличением числа циклов деформирования поверхностей увеличивалась площадь фактического контакта. При этом поле напряжений перераспределялось таким образом, что максимальное контактное давление концентрировалось в крайних зонах контакта. Действие касательного усилия ускоряло разупрочнение граничной зоны контакта и вызывало появление микротрещин усталости. Замечено, что площадь пятна контакта под медным контробразцом в период приработки увеличивалась быстрее, чем в стальных парах.

В случае контакта стали со сталью и стали с медью было обнаружено равенство коэффициентов трения, несмотря на более высокую долговечность пары сталь-медь при одинаковых условиях испытаний. Это явление можно видимо объяснить различием в напряженном состоянии материала образца в крайних зонах пятна контакта при действии различных материалов контр-образца (сталь-сталь, сталь-медь). Следовательно, максимальное напряжение при контакте стали со сталью должно быть выше, чем на контакте стали с медью при одном и том же значении нормальной силы. Не трудно предположить, что и напряжения в крайних точках стального контакта будут больше. В таких условиях зарождение микротрещин усталости в пятнах фреттинга для контакта стали с медью, можно ожидать значительно позднее, что подтвердили результаты испы- 
таний. Зарождение микротрещин на контакте стали со сталью и стали с медью наблюдалось, в основном на границах пятна контакта в зонах наибольших напряжений, меняющих свой знак синхронно циклическому нагружению.

\section{Выводы:}

1. Разработана методика исследования фреттинг-процессов в пятне контакта при сложном нагруженном состоянии. Исследования по данной методике позволяют разработать наиболее рациональную форму деталей в сопряжении, обеспечивающую благоприятное распределение напряжений на контактных поверхностях сопрягаемых деталей.

2. На специально изготовленной испытательной машине исследовались процессы фреттинг-усталости, фреттинг-коррозии и фреттингизноса в пятне контакта, что позволило детально изучить все факторы при фреттинге и дало возможность разработать рекомендации по борьбе с ним: подбор материалов контактирующих пар в сопряжении, технологические способы обработки поверхностей, использование твердых и жидких смазок, конструктивное решение узлов в сопряжениях.

\section{ЛIТЕРАТУРА}

1. Балаччкий, Л.Т. Прочность прессовых соединений. К.: Техніка, 1982. $180 \mathrm{c}$.

2. Похмурский, В.И., Филимонов, Г.Н., Балацєий, Л.Т. О выборе базового числа нагружений при испытании на выносливость в условиях фретттинга // Технология судостроения. 1983. № 3.

3. Pokhmurskyi, V.I. and Kalakhan, O.S. Plasma Coatings and Their Ability to Protect Titanium Alloys Against Corrosion FrettingFatique Fracture // Material Science. 1997. 33, № 3. P 331-335.

4. Похмурский, В.И., Мацевітий, В.М., Калахан, О.С. та ін. Розробка та дослідження покриттів для захисту від фреттингкоррозіі // Проблеми машинознавства. 2009. № 5. С. 23-29.

5. Балацкий, Л.Т., Бабинецьь, В.И., Филимонов, Г.Н. Повышение сопротивления усталости валов в зоне фреттинга. К.: Проблемы прочности, 1984. С. 109-111.

6. Parson, B., Wilson, E.A. F mtthod for determining the surface contact stresses resulting from interference fits. Trans of the $\mathrm{Na}$ tional Fdvisory Committee for Aeronautics. B - 92, No.L. 1970. 
ВІСНИК

ОДЕСЬКОГО НАЦІОНАЛЬНОГО

МОРСЬКОГО УНІВЕРСИТЕТУ

№ 2 (65), 2021
HERALD

OF THE ODESSA NATIONAL

MARITIME UNIVERSITY

№ 2 (65), 2021

7. Бабинеи, В.И., Балачкий, Л.Т., Похмурский, В.И. Устройство для испытания материалов на износ при циклическом изменении напряженного состояния. Авторское свидетельство № 877406 по заявке № 2886672 с приоритетом 20.02.1980 г. Зарегистрировано в Государственном реестре изобретений СССР 01.07.19812.

8. Распределение нормальных напряжений на поверхности фрикционного контакта / Г.А. Гороховский, Э.А. Клюев и др. // Проблемы прочности и изнашивания. 1976. Bып.10. С.15-18.

9. Напряженное состояние в зоне контакта полиуретана твердым индентором / Э.А. Клюев и др. // Механика полимеров. 1976. № 5. C.15-18.

10. Похмурьский, В.І., Хама, М.С. Коррозійна втома металів $i$ сплавів. Львів: СПОЛОМ, 2008.

\section{REFERENCES}

1. Balatsky, L.T. The strength of the press connections. K.: Technica. 1982. $180 \mathrm{p}$.

2. Pokhmursky, V.I., Filimonov, G.N., Balatsky, L.T. On the choice of the base number of loads during endurance testing under fretting conditions // Shipbuilding technology. 1983. № 3.

3. Pokhmurskyi, V.I. and Kalakhan, O.S. Plasma Coatings and Their Ability to Protect Titanium Alloys Against Corrosion FrettingFatique Fracture // Material Science - 1997. 33, No. 3. R 331-335.

4. Pokhmursky, V.I., Matsevitiy, V.M., Kalakhan, O.S. Et al Development of that doslijennya pokrittiv for zagistu vid frettingcorrosion // Problems of machine learning. 2009. № 5. P. 23-29.

5. Balatsky, L.T., Babinets, V.I., Filimonov, G.N. Increased fatigue resistance of shafts in the fretting zone. G. "Problems of Strength», 1984, p. 109-111.

6. Parson, B., Wilson, E.A. F mtthod for determining the surface contact stresses resulting from interference fits. Trans of the National Fdvisory Committee for Aeronautics. B - 92, No.L. 1970.

7. Babinets, V.I., Balatsky, L.T., Pokhmursky, V.I. A device for testing materials for wear at cyclic changes in the stress state. Inventor's certificate No. 877406 for application No. 2886672 with a priority of 20.02.1980. Registered in the State Register of Inventions of the USSR on 07/01/1981.

8. Distribution of normal stresses on the surface of the frictional contact / G.A. Gorokhovsky, E.A. Klyuev, et al. // Problems of strength and wear. 1976. issue 10. P. 15-18. 
ВІСНИК

ОДЕСЬКОГО НАЦІОНАЛЬНОГО

МОРСЬКОГО УНІВЕРСИТЕТУ

№ 2 (65), 2021
HERALD

OF THE ODESSA NATIONAL

MARITIME UNIVERSITY № 2 (65), 2021

9. Stress state in the zone of polyurethane contact with a solid indenter / EA. Klyuev et al. // Mechanics of Polymers. 1976. № 5. P.15-18.

10. Pokhmursky, V.I., Homa, M.S. Corrosion in metal i alloy. Lviv: SPOLOM, 2008.

Стаття надійшла 08.04.2021

Посилання на статтю: Кобзарук А.В., Бабинец В.И. Исследование фреттинг-процессов при циклическом изменении напряженного состояния в пятне контакта // Вісник Одеського національного морського університету: 3б. наук. праць, 2021. № 2(65). C. 138-151. DOI 10.47049/ 2226-1893-20212-138-151.

Article received 08.04.2021

Reference a JournalArtic: Kobzaruk Olexander, Babinets Valery. Research of fretting processes in cyclic changes in the voltage state at the contact spot // Herald of the Odessa national maritime university. 2021. 2(65). C. 138-151. DOI 10.47049/ 2226-1893-2021-2-138-151. 